\title{
Role of Sleep in Memory
}

\author{
${ }^{1}$ Racheal Fernandes, ${ }^{2}$ Preeti Devnani
}

\begin{abstract}
Sleep is essential to our survival. The various stages of sleep play a significant role in brain maturation. Memory is an important essential feature of the human brain. Memory is information that is encoded, retained, and recalled. This review summarizes various subtypes of memory and provides insight into the role of sleep in the formation of memory and the impact of sleep deprivation.
\end{abstract}

Keywords: Memory formation, Sleep deprivation and memory.

How to cite this article: Fernandes R, Devnani P. Role of Sleep in Memory. Indian Sleep Med 2017;12(2):12-14.

\section{Source of support: Nil}

Conflict of interest: None

\section{INTRODUCTION}

Sleep is not just "time out" from daily life. Sleep is an active dynamic process and is important for renewing our mental and physical health each day. There are recognized stages of sleep, each of which is identified by a characteristic brain wave activity. While we sleep, we pass through different phases of sleep, nonrapid eye movement N1, N2, N3, and rapid eye movement (REM) sleep. ${ }^{1}$ Sleep and wakefulness are influenced by various neurotransmitters, namely serotonin, norepinephrine, epinephrine, dopamine signals in the brain.

There are different theories postulated to explain memory. Plato (423-348 вс) believed that memory is a craft perfected through philosophical dialogue. Ancient Roman rhetorician Aristotle (384-322 BC) referred memory to be a "storehouse metaphor." He compared memory with making impressions in wax. Marcus Tullius Cicero (106-43 вс) developed his idea of memory from Aristotle that the mind is a storehouse of memory that can be recalled for rhetorical practice. ${ }^{2}$ Memory is the information received from the environment we store; it is the brain's ability to encode information that is received from the surrounding, stored, retained, and past experiences recalled whenever needed in the future for survival.

Sleep is a state that optimizes the consolidation of newly acquired information in memory, and is dependent

\footnotetext{
${ }^{1}$ Clinical Cordinator, ${ }^{2}$ Clinical Director

1,2Sleep Disorders Clinic, Mumbai, Maharashtra, India

Corresponding Author: Preeti Devnani, 1st Agnelo House S.V. Road, Khar West, Mumbai, Maharashtra, India, e-mail: drdevnani@gmail.com
}

on the specific conditions of learning and the timing of sleep periods.

There are two broad types of memory: Short memory and long-term memory. It is generally assumed that there are two kinds of memory: Natural memory, those that are inborn memory that are required to live our day-to-day life, and artificial memory, those that are acquired during the course of our lives. Memory is essential to behavior, enabling organisms to draw on past experience to guide choices and actions.

\section{TYPES OF MEMORY}

The human memory is divided into sensory memory, short-term memory (working memory), and long-term memory (Flow Chart 1), each of which has a particular mode of operation and is involved in the process of memorization.

Sensory memory is an impression of sensory information received from sensory organs after the original stimuli has ended. This memory lasts for about a few seconds. Short-term memory requires conscious awareness. Long-term memory is further described: (1) Explicit memory is also known as declarative memory. Declarative memory is a conscious recollection of memory, such as remembering telephone numbers, song, or an image of a past event. Declarative memory are of two types: Episodic and semantic. Episodic memory is based on personal experiences, emotions, and feelings. The entire context experienced during that event would form a part of the memory. Semantic memory are facts, concepts that are acquired by an individual, simply known as knowledge of the world. Semantic memory would include capital cities, types of food, social customs, etc.

Flow Chart 1: Types of memory

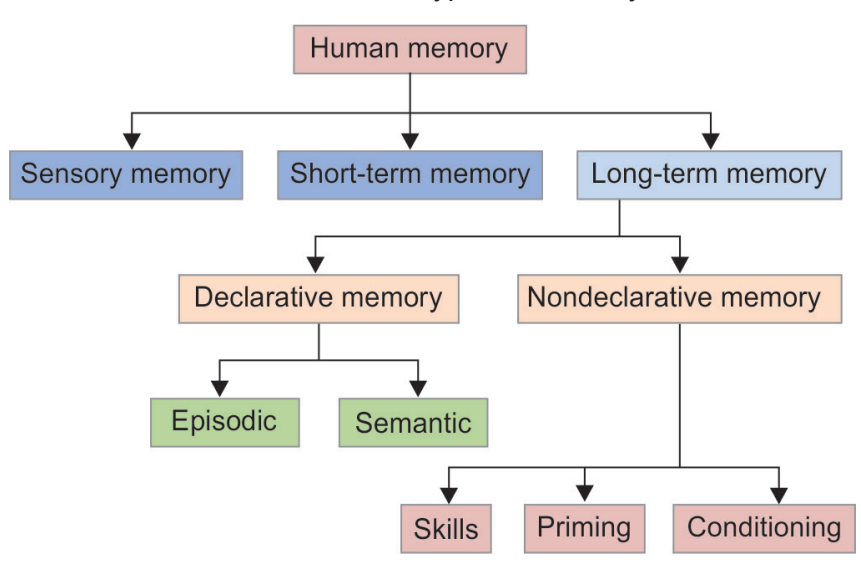


(2) Implicit memory is also known as nondeclarative or procedural memory. Implicit memory refers to the "how to" aspects of our behavior. This kind of memory is not available to consciousness; it is acquired and retrieved at an unconscious level. Implicit memory includes skills, priming, and conditioning. Skills and emotional associations with particular stimuli or events, which form our likes and dislikes, are those that are learnt during our course in a lifetime. Priming is remembering something that is recently seen or heard, i.e., the ability to identify an item as a result of previous exposure to it, even if you are unaware of the previous exposure, a phenomenon well known to advertisers. Linking a set of nonrelated stimuli and responses is known as conditioning. ${ }^{3}$

\section{NEUROBIOLOGY OF MEMORY}

The process involved in the formation of memory is not known, but the process follows the trend of acquisition, consolidation, and recall.

Acquisition is when new information is introduced to the brain. The brain receives information through the sensory system and is processed by the sensory association cortex. This new information is then encoded and it is held as working memory or short-term memory. If this information is attended to, then it undergoes the process of consolidation. Consolidation is the process by which the memory is made stable and hence can be recalled when needed so. Recall is the process by which the data are retrieved any time in the future.

Acquisition and recall are events that occur when you are in wake condition. Consolidation occurs during sleep. Consolidation originates from reactivation of recently encoded neuronal memory representations, which occur during slow wave sleep (SWS) and transform respective representations for integration into long-term memory.

\section{ROLE OF SLEEP IN MEMORY FORMATION}

Memory is not uniform; it is processed by different brain structures and is differentially influenced by sleep stages. Research has shown that sleep benefits the retention of memory. Loss of sleep and disruption of REM, which could be secondary to sedative drugs or endocrine imbalance, such as with thyroid glands, alcohol can all disrupt normal hippocampal function. ${ }^{4}$ Various sleep stages are involved in the consolidation of different types of memory. Sleep deprivation reduces one's ability to learn.

Learning induces distinct and prolonged waves of REM increases and is possibly involved in memory formation. The increase in REM sleep during the specific time periods predicts later memory recall, and reliably separates between learners and nonlearners. ${ }^{5}$ A study showed that repeated arousals from REM sleep foster serious emotional and cognitive disturbances. These disturbances impair performance at the time of memory retrieval, hence proving the fact that REM sleep is required for consolidation. ${ }^{6}$ Research showed that individuals engaged in an intensive language course were observed to have an increase in REM sleep. ${ }^{7}$ The REM sleep, predominating late sleep, is required for the formation of emotional memory in humans. ${ }^{8}$ Early sleep dominated by SWS selectively improves consolidation of declarative tasks (paired-associate words, spatial rotation) but does not improve memory for the procedural tasks of the studies (mirror tracing, word stem priming). ${ }^{9,10}$

\section{SLEEP DEPRIVATION AND MEMORY}

Sleep is essential for cognitive performance, especially memory consolidation. ${ }^{11}$

Sleep deprivation leads to reduced alertness, cognition, performance, and has a negative impact on health secondary to both of reduced total sleep time (decreased quantity) or fragmentation of sleep by brief arousals (decreased quality).

Acute sleep deprivation refers to no sleep or a reduction in the usual total sleep time, usually lasting 1 or 2 days. Chronic sleep deprivation is when individual routinely sleeps less than the amount required for optimal functioning. The most common causes of sleep deprivation are those related to contemporary lifestyle and workrelated factors, thus impacting a considerable section of society. A chronic reduction in the sleep time or the fragmentation of sleep, leading to the disruption of the sleep cycle, has consequences like cognitive functions, attention, and operant memory. ${ }^{12}$

Sleep deprivation is common in many occupations that demand 24 hour operations, such as nursing, mining, trucking, and aviation, and tragically, sleep deprivation has been implicated in several catastrophic incidents and accidents. ${ }^{13}$ Studies measure the effects of call rotations on sleep-wake times and working memory capacity (WMC) in 37 internal medicine residents. On-call rotation in the first month had a confounding detrimental effect on WMC. A month of call rotations reduced overall sleep per night; sleep hours per night were variable; and WMC was adversely affected. Decreased WMC could explain impaired judgment during sleep deprivation. ${ }^{14}$ This has led to enforcement of safety guidelines on rotations in training doctors.

\section{SLEEP REQUIREMENT IN THE DEVELOPMENT OF BRAIN AND ROLE IN MEMORY FORMATION}

Newborn infants spend up to $70 \%$ of their time asleep with very little time for wakefulness. ${ }^{15}$ The first few months of a neonate is about rapid learning of the 
environment. The sleep requirement of an infant differs as compared with older children and adults. Active sleep may facilitate neural processes, such as synapse formation and pruning by providing endogenous stimulation to the brain. ${ }^{16}$ A study has shown that short sleep duration in the first 3 years of life was associated with hyperactivity / impulsivity and lower cognitive performance on neurodevelopmental tests at age 6, is provocative, and potentially very important. ${ }^{16}$ Evidence shows that infants (6 months and 12 months) who napped for $\geq 30$ minutes in comparison to those who did not nap performed better in retaining their memory for new behaviors across a 4- and 24-hour delay. Therefore, infants depend on frequent naps for declarative memory consolidation and the formation of long-term memory. ${ }^{17}$ This proves that sleep plays an important role in brain development and long-term memory among children.

\section{CONCLUSION}

In this review, the impact of sleep on the formation of memory, its role in brain development, and the deleterious outcome of sleep deprivation in the formation of memory are highlighted. External cues, i.e., zeitgebers, such as sunlight, caffeine, excessive medications, and previous sleep periods, influence our wake and sleep states. We need to increase education and public awareness across multiple platforms and all age group, parents, educators, and health care professionals to have a positive impact on the well-being of society.

\section{REFERENCES}

1. Carskadon, MA.; Dement, WC.; Meir, HK., et al. Normal human sleep: an overview. In: Kryger MH, Roth T, Dement WC, editors. Principles and practice of sleep medicine. 5th ed. St. Louis (MO): Elsevier Saunders; 2011. pp. 16-26.

2. Freedheim, DK.; Weiner, IB. Handbook of Psychology. In: Freedheim DK, editor. History of psychology. Vol. 1. Hoboken (NJ): John Wiley \& Sons, 2012. pp. 111-113.
3. Purves, D.; Augustine, GJ.; Fitzpatrick, D., et al., editors. Neuroscience. 2nd ed. Qualitative Categories of Human Memory. Sunderland (MA): Sinauer Associates; 2001.

4. Brand N, Hanson E, Godaert G. Chronic stress affects blood pressure and speed of short-term memory. Percept Mot Skills 2000 Aug;91(1):291-298.

5. Rasch B, Born J. About sleep's role in memory. Physiol Rev 2013 Apr;93(2):681-766.

6. Horne JA, McGrath MJ. The consolidation hypothesis for REM sleep function: stress and other confounding factors-a review. Biol Psychol 1984 May;18(3):165-184.

7. Ellenbogen JM, Payne JD, Stickgold R. The role of sleep in declarative memory consolidation: passive, permissive, active or none? Curr Opin Neurobiol 2006 Dec;16(6):716-722.

8. Wagner U, Gais S, Born J. Emotional memory formation is enhanced across sleep intervals with high amounts of rapid eye movement sleep. Learn Mem 2001 Mar-Apr;8(2): 112-119.

9. Plihal W, Born J. Effects of early and late nocturnal sleep on priming and spatial memory. Psychophysiology 1999 Sep;36(5):571-582.

10. Plihal W, Born J. Effects of early and late nocturnal sleep on declarative and procedural memory. J Cogn Neurosci 1997 Jul;9(4):534-547.

11. Stickgold R, Hobson JA, Fosse R, Fosse M. Sleep, learning, and dreams: off-line memory reprocessing. Science 2001 Nov;294(5544):1052-1057.

12. Orzeł-Gryglewska J. Consequences of sleep deprivation. Int J Occup Med Environ Health 2010 Dec;23(1):95-114.

13. Mitler MM, Carskadon MA, Czeisler CA, Dement WC, Dinges DF, Graeber RC. Catastrophes, sleep and public policy: consensus report. Sleep 1988 Feb;11(1):100-109.

14. Gohar A, Adams A, Gertner E, Sackett-Lundeen L, Heitz R, Engle R, Haus E, Bijwadia J. Working memory capacity is decreased in sleep-deprived internal medicine residents. J Clin Sleep Med 2009 Jun;5(3):191-197.

15. Tarullo AR, Balsam PD, Fifer WP. Sleep and infant learning. Infant Child Dev 2011 Jan;20(1):35-46.

16. Touchette E, Petit D, Séguin JR, Boivin M, Tremblay RE, Montplaisir JY. Associations between sleep duration patterns and behavioral/cognitive functioning at school entry. Sleep 2007 Sep;30(9):1213-1219.

17. Seehagen S, Konrad C, Herbert JS, Schneider S. Timely sleep facilitates declarative memory consolidation in infants. Proc Natl Acad Sci 2015 Feb;112(5):1625-1629. 